\title{
Micromorphology Memory in Amphiphilic Polypeptides
}

\author{
Tatsuo Kaneko, ${ }^{1, \dagger}$ Taiki ShimoKuri, ${ }^{1}$ Shinji Tanaka,,${ }^{1,2}$ and Mitsuru AKashi ${ }^{1, \dagger \dagger}$ \\ ${ }^{1}$ Department of Molecular Chemistry, Graduate School of Engineering, \\ Osaka University, 2-1, Yamadaoka, Suita 565-0871, Japan \\ ${ }^{2}$ Tsukuba Research Laboratory, NOF Corporation, \\ 5-10 Tokodai, Tsukuba 300-2635, Japan
}

(Received September 8, 2006; Accepted April 16, 2007; Published May 29, 2007)

\begin{abstract}
Micromorphology memory was observed using thin films of PEGylated polypeptides, poly\{ $\beta$-benzyl-L-aspartate) (BLA)-block-ethylene glycol (EG)-block-BLA\}. The slow vaporization of polymer dichloromethane solutions led to the formation of multi-spherulite films, which disappeared upon heating above the PEG melting temperature, $57^{\circ} \mathrm{C}$, but reappeared by successive cooling, down to $30^{\circ} \mathrm{C}$, thereby changing the spherulite interface morphology. The water-immersion of recrystallized films caused the self-assembly of peptide chains to form water-swollen networks with spherulites, but surprisingly, spherulite interface morphologies remained completely the same as oncedisappeared morphologies in the original dry films. A similar memory behavior was also observed in the pattern inside a milliscaled spherulite which entirely occupied the network. Spectroscopic and microscopic studies suggest that appropriate peptide conformations are very important for memorized micromorphology.

[doi:10.1295/polymj.PJ2006109]

KEY WORDS Triblock Copolymers / Spherulites / Shape-memory / Self-assembly / Polypeptides / Micromorphology /
\end{abstract}

The memory of the organic system has attracted researcher's attention in terms of life sciences such as immunology and brain science, and material fields such as molecular machines and electronic devices. Macromolecular helical forms were memorized regardless of chirality ${ }^{1}$ and hydrogel macroscopic forms were memorized by supporting changeable cross-linking junctions. ${ }^{2}$ However a key factor in the life action and the material development is rather in molecular aggregates, as cells move based on changes in protein-assembly forms of myosine bundles with actin. ${ }^{3}$ Micromorphology memory, regarding macromolecular chain self-assembly has never been observed as far as we know, although the memory based on the multistable state in the crystalline or liquid crystalline state has been seen on the nanoscale level. ${ }^{4}$

In previous papers, we synthesized an ABA-type triblock copolymer comprised of poly $(\beta$-benzyl-Laspartate) (PBLA) as a hydrophobic (A) segment and poly(ethylene glycol) (PEG, number-average molecular weight, $M_{\mathrm{n}}=20,300$, a polymerization degree $\mathrm{Dp}=460$ ) as a hydrophilic (B) segment. ${ }^{5-7}$ The copolymers had monodispersed chain lengths and excellent cell compatibility. ${ }^{7}$ Although ABA-type triblock copolymers containing PEG as a B block were widely studied and the importance of interblock interactions on the mutual crystallization behavior following thermal treatment has been reported, ${ }^{8}$ there are no reports on block copolymers containing long PEG blocks with Dp of more than 200, except for ours. In the course of studies on in situ hydrogelation of triblock PBLAPEO-PBLA copolymers with long PEO blocks, we found a micromorphology memory of the copolymer spherulites by water-immersion. Herein we report such a unique behavior and the relationship between the micromorphology memory and peptide structures. The appropriate peptide conformation was indispensable for memory induction.

\section{EXPERIMENTAL}

\section{Materials}

Polyethyleneglycol (PEG) with diamino end groups is commercially available $\left(M_{\mathrm{n}}=20,300\right.$, NOF Corporation, Japan), and was used without further purification as an initiator of $\beta$-benzyl-L-aspartate $\mathrm{N}$-carboxyanhydride (BLA-NCA) polymerization). Dehydrated dichloromethane (Kanto Kagaku, Japan) and N,Ndimethylformamide (DMF, water content $<30 \mathrm{ppm}$, Wako Chemical Co. Ltd. Japan) were also used for polymerization as purchased from the manufacturer. BLA-NCA was prepared by the method of Goodman et al. ${ }^{9}$

\section{Synthesis}

PEGylated PBLAs were precisely synthesized in

\footnotetext{
${ }^{\dagger}$ To whom correspondence should be addressed (Tel: +81-6-6879-7357, Fax: +81-6-6879-7359, E-mail: akashi@ chem.eng.osaka-u.ac.jp).

${ }^{\dagger \dagger}$ Present Address: School of Materials Science, Japan Advanced Institute of Science and Technology, 1-1 Asahidai, Nomi, 923-1292 Japan
} 
Table I. Synthesis and Characterization of ABA-Triblock Copolymers Poly(BLA- $b$-EG- $b$-BLA) ${ }^{\mathrm{a}}$

\begin{tabular}{|c|c|c|c|c|c|c|c|}
\hline \multirow[b]{2}{*}{ Designation $^{\mathrm{b}}$} & \multirow[b]{2}{*}{$\begin{array}{c}\text { BLA/EG } \\
\text { (mole/mole) } \\
\text { in feed }\end{array}$} & \multicolumn{6}{|c|}{ Triblock copolymers } \\
\hline & & $\begin{array}{c}M_{\mathrm{w}}{ }^{\mathrm{c}} \\
(\mathrm{GPC}) \\
\times 10^{-4}\end{array}$ & $\begin{array}{c}M_{\mathrm{n}}{ }^{\mathrm{c}} \\
(\mathrm{GPC}) \\
\times 10^{-4}\end{array}$ & $M_{\mathrm{w}} / M_{\mathrm{n}}^{\mathrm{c}}$ & $\begin{array}{c}M_{\mathrm{n}}^{\mathrm{d}} \\
\left({ }^{1} \mathrm{H} \text { NMR }\right) \\
\times 10^{-4}\end{array}$ & Dp of PBLA ${ }^{\mathrm{d}}$ & $\begin{array}{c}\text { BLA/EG } \\
\text { (mole/mole) } \\
\text { in copolymers }\end{array}$ \\
\hline $\mathrm{Dp}=18$ & 0.085 & 2.9 & 2.8 & 1.04 & 2.8 & 18 & 0.078 \\
\hline $\mathrm{Dp}=25$ & 0.116 & 2.8 & 2.7 & 1.04 & 3.1 & 25 & 0.109 \\
\hline $\mathrm{Dp}=32$ & 0.148 & 3.8 & 3.6 & 1.07 & 3.3 & 32 & 0.139 \\
\hline
\end{tabular}

a) BLA refers to $\beta$-benzyl-L-aspartate and EG refers to ethylene oxide. Poly(BLA-block-EG-block-BLA) was prepared by the ring-opening polymerization of the BLA N-carboxy anhydride initiated by amino terminal groups of diamino PEG (numberaverage molecular weight, $\left.M_{\mathrm{n}}=20,300\right)$. b) Dp refers to degree of polymerization of PBLA blocks estimated by ${ }^{1} \mathrm{H}-\mathrm{NMR}$. c) $M_{\mathrm{n}}$, and weight-average molecular weight, $M_{\mathrm{w}}$, and polydispersity, $M_{\mathrm{w}} / M_{\mathrm{n}}$, were measured by gel permeation chromatography using PEG standards. d) Dp in one block was determined from the ratio of integral resonance peak values for PEG segments at $3.6 \mathrm{ppm}\left(-\mathrm{O}-\mathrm{CH}_{2} \mathrm{CH}_{2-} ; 4 \mathrm{H}\right)$ to those for PBLA segments at $7.3 \mathrm{ppm}\left(\mathrm{C}_{6} \mathrm{H}_{5}-; 5 \mathrm{H}\right)$.

the following procedure. The ring-opening polymerization of BLA-NCA was performed without a catalyst for $24 \mathrm{~h}$ at $40^{\circ} \mathrm{C}$ in a nitrogen atmosphere. Initiation from the amine-terminated PEG $(10 \mathrm{w} / \mathrm{v} \%)$ in the mixture of dichloromethane/DMF $(9 / 1, \mathrm{v} / \mathrm{v})$, lead to a variation in the molar composition of BLA-NCA to the ethylene glycol (EG) units in the feed from 39 to 119 (mol \%) (Table I). The polymerization proceeded homogeneously and the reaction solution was poured into a large quantity of hexane/ethyl acetate $(1 / 1, v / v)$ to precipitate the white matter. Products were washed with hexane and then dried in vacuo at room temperature, yielding P(BLA- $b$-EG- $b$-BLA) triblock copolymers (yields: over $98 \mathrm{wt} \%$ based on PEG recovery). Structures were confirmed by infrared (IR) spectroscopy and proton nuclear magnetic resonance $\left({ }^{1} \mathrm{H}-\mathrm{NMR}\right)$, and also by gel permeation chromatography.

\section{Film Preparation}

Dry films were prepared by casting from a dichloromethane solution $(3 \mathrm{~mL}, 1 \mathrm{w} / \mathrm{v} \%)$ of PEGylated PBLA on a flat Teflon ${ }^{\circledR}$ dish $(\phi: 50 \mathrm{~mm})$, and the dichloromethane was spontaneously vaporized at $25^{\circ} \mathrm{C}$.

\section{Measurements}

The $M_{\mathrm{n}}$, weight-average molecular weight $\left(M_{\mathrm{w}}\right)$ and polydispersity $\left(M_{\mathrm{w}} / M_{\mathrm{n}}\right)$ of copolymers were measured by gel-permeation chromatography (GPC) using a TOSOH SG-8020 liquid chromatograph equipped with a PEG-calibrated TSK gel column (G3,000H HR or G4,000H HR) and an internal RI detector (RI-8022). DMF containing $10 \mathrm{mM} \mathrm{LiCl}$ was used as an eluent at a flow rate of $0.8 \mathrm{~mL} / \mathrm{min}$ at $40^{\circ} \mathrm{C}$.

${ }^{1} \mathrm{H}-\mathrm{NMR}$ spectra of copolymers were measured at $353 \mathrm{~K}$ in dimethylsulfoxide- $d_{6}$, (DMSO- $\left.d_{6}\right)$, on a JEOL JNM-EX270 FT NMR spectrometer, to estimate copolymer compositions and molecular weights of PBLA blocks, using the residual proton resonance of DMSO-d6 as an internal standard (2.55 ppm).

FT-IR spectra of copolymer films were measured on a Perkin Elmer Spectrum One spectrometer between $4000-400 \mathrm{~cm}^{-1}$. Crossed-polarizing microscopic images were taken with an Olympus BX51 microscope equipped with a digital camera and a programmable temperature controller (resolution: $\pm 0.1 \mathrm{~K})$. The $\beta$-strand content to the whole PBLA chain was estimated from the peak area ratio of $1657 \mathrm{~cm}^{-1}$ to $1635 \mathrm{~cm}^{-1}$ using peak fitting software (GRAMS/AI ver.7, Thermo Galactic).

$\mathrm{X}$-Ray diffraction patterns (XRD) were recorded on an X-ray diffractometer (RINT UltraX18) equipped with a scintillation counter using $\mathrm{CuK} \alpha$ radiation $(40 \mathrm{kV}, 200 \mathrm{~mA}$; wavelength $=1.5418 \AA)$, which was monochromated by a parabolic multilayer mirror in reflection geometry.

Transmission electron microscopic (TEM) images of stained ultrathin cross-sections for dry polymer films were measured with a Hitachi H-7100FA TEM operated at an acceleration voltage of $100 \mathrm{kV}$. Freeze-dried films embedded in epoxide resin were cut with a diamond knife (DiATOME ULTRA Cryo Dry) in a ultramicrotome system (Leica EM-Ultracut-UCT, EM-FCS cryosystem) to yield ultrathin cross sections with less than $0.1 \mu \mathrm{m}$ thickness as TEM specimens. Sections were put on a copper mesh and dried under reduced pressure. Specimens were stained by a vapor of ruthenium tetraoxide.

\section{RESULTS AND DISCUSSION}

\section{Structure in Dry State}

We prepared ABA-type triblock copolymers, poly$\{(\gamma$-benzyl-L-aspartate) (BLA)-block-ethylene glycol (EG)-block-BLA\}, with narrow-distributed chain lengths (degree of polymerization for BLA units, $\mathrm{n}: 18,25,32$; polydispersity: $1.04-1.07$ ) by the ring- 


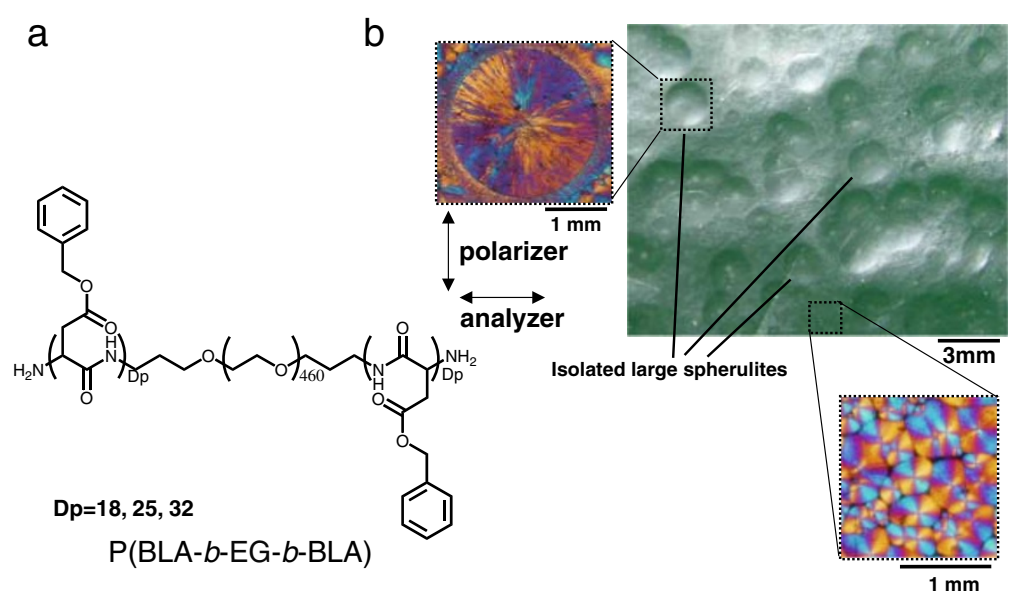

Figure 1. a) Chemical Structures of triblock copolymers, poly $\{(\gamma$-benzyl-L-aspartate) (BLA)-block-ethylene oxide (EG)-block-BLA $\}$ s. b) The representative photo of the triblock copolymer film $(\mathrm{Dp}=25)$ prepared by the stepwise drying of its dichloromethane solution. Close-up views of the polarized microscopic photo with a first-order retardation plate $(\lambda=530 \mathrm{~nm})$ in the light path are inset left and bottom. The direction of crossed polarizers is shown left.

opening polymerization of BLA N-carboxyanhydride (NCA) initiating at both amine terminal groups of a PEG diamine $\left(\mathrm{Dp}=460, M_{\mathrm{n}}=20,300\right)$ by a previously-reported procedure ${ }^{5}$ (copolymer structure: Figure 1a). Dichloromethane (DCM) solutions of copolymers $(1 \% \mathrm{w} / \mathrm{v} ; 10 \mathrm{~mL})$ on Teflon ${ }^{\mathrm{TM}}$ petri dishes were spontaneously dried, and thin films with a number of micrometer-sized spherulites were formed. On the other hand, a slow drying of copolymers in a desiccator $(12 \mathrm{~L})$ over three $\mathrm{d}$ formed much larger millimeter-sized spherulites than with spontaneous drying. However, spherulites in either case were not circular but had polygonal uneven morphologies. When we opened the cap of the desiccator to accelerate the drying speed two d after slow-drying the DCM solution, a sea-island structure comprised of a milli-spherulite island and a micro-spherulite sea was formed; several milli-spherulites lay in the $1 \times 1 \mathrm{~cm}^{2}$ region, while 500-600 micro-spherulites surrounded them as shown in the representative photo of the copolymer with a BLA unit of $\mathrm{Dp}=25$ (Figure $1 \mathrm{~b}$ ). The two-step drying method created about 10 isolated millimeter-scaled spherulites with a complete circular form. Drying acceleration might restrict the growth of milli-spherulites around which many micro-spherulites appeared by increasing the nucleation frequency of spherulites, to isolate milli-spherulites. The isolation indicates an interference in which milli-spherulites collide with one another to form a uniform circular morphological formation. Thus we controlled Spherulite signs were estimated using a first-order retardation plate $(\lambda=530 \mathrm{~nm})$ inserted in the light path under a crossed-polarizing microscope (left and bottom photos inset in Figure 1b). Micro-spherulites were negative, as evidenced by additive birefringence (orange color) in the first and third quadrants (upper- right and lower-left quarters, respectively) of spherulites, while milli-spherulites were positive, as evidenced by subtractive birefringence (blue color) in the same quadrants. Generally the spherulite sign is derived from the chain orientation along or across the spherulite circle. ${ }^{10}$ In X-ray diffraction (XRD) diagrams of as-cast films (Figure 2a), some intense diffraction peaks assigned to PEG crystals ${ }^{11}$ appeared in the $2 \theta$ ( $\theta$ : diffraction angle) range more than $10^{\circ}$ while a very weak peak of PBLA blocks ${ }^{12}$ appeared at $2 \theta=5^{\circ}$, indicating that spherulites formed mainly as a result of PEG block crystallization. In addition, a sharp diffraction peak appeared at $2 \theta=2^{\circ}$ corresponding to a d-spacing of $4.4 \mathrm{~nm}$, which demonstrates the formation of a long-range structure. IR/ ATR spectra of the as-cast film (Figure 2b) show amide distinct peaks at $1657 \mathrm{~cm}^{-1}$ (s, amide I) and $1552 \mathrm{~cm}^{-1}$ (s, amide II) assigned to $\alpha$-helical conformations of PBLA blocks according to the literature, and beside that peak, very tiny amide shoulders at 1635 (amide I) and $1531 \mathrm{~cm}^{-1}$ (amide II) are assigned to $\beta$-strands. ${ }^{13}$ The $\beta$-strand percentage to whole PBLA chains was estimated using peak fitting software (GRAMS/AI ver.7, Thermo Galactic) to be 5\% for $\mathrm{Dp}=18,3 \%$ for $\mathrm{Dp}=25$, and $5 \%$ for $\mathrm{Dp}=32$. Since PEG chains had a refractive index ellipsoid whose longitudinal axis was along the chain axis, ${ }^{14}$ most of PEG chains might orient radially inside milli-spherulites while they oriented circularly inside micro-spherulites.

\section{Micromorphology Memory in Hydrogelation}

The film was easily cut into rectangular sheets with micro- and milliscaled spherulite domains as shown in Figure 3a. The film was melted and adhered to the glass surface upon heating above $57^{\circ} \mathrm{C}$, which corre- 

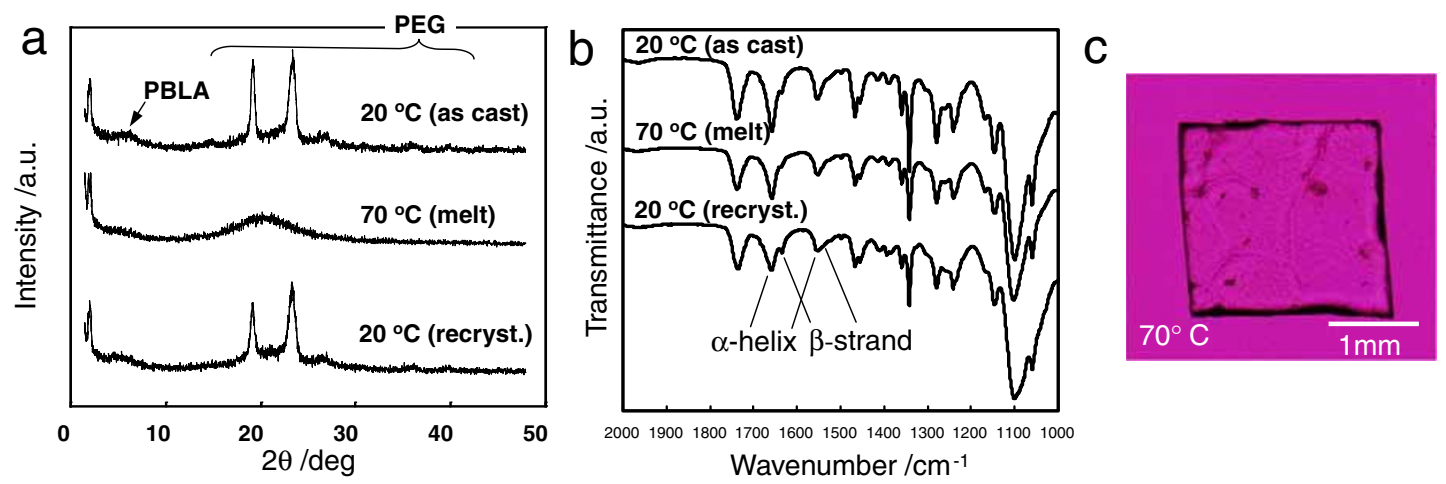

Figure 2. a) X-Ray diffraction (XRD) patterns of triblock copolymer films ( $\mathrm{Dp}=25)$. b) Fourier-transformed Infrared (FT-IR/ATR) spectra of triblock copolymer films $(\mathrm{Dp}=18)$. c) Crossed-polarizing microscopic photos of triblock copolymer films $(\mathrm{Dp}=25)$ taken at $70^{\circ} \mathrm{C}$ with a first-order retardation plate $(\lambda=530 \mathrm{~nm})$.

sponds to the melting point of PEG segments. The spherulites disappeared and the film became invisible under the cross-nicol although one can faintly see the boundaries of original spherulites under the first-order retardation plate (Figure 2c). Recrystallization occurred during successive cooling from $70^{\circ} \mathrm{C}$ and new spherulites whose morphologies were irregular and different from original spherulites filled the sheet (Figure 3b). The spherulite sign was still negative as shown in the upper photo of Figure 3b. When the recrystallized sheet was immersed into water, the film was swollen to attain an equilibrated water-swollen state within $5 \mathrm{~min}$. The degree of swelling, q, which was the ratio of the film weight in the swollen state to that in the dry state was 5.8, 5.4, and 4.4, decreasing with an increase in Dp from 18, 25, and 32, respectively. Although we could not discern swollen gels through a pair of microscopic eye-lenses, a highlysensitive CCD camera (12M picture elements) clearly caught the birefringence of water-swollen films to confirm the formation of distinct spherulites showing clear Maltese crosses and boundaries as widely seen in single spherulites of low-molecular weight molecules (lower photo of Figure 3c). Maltese crosses retained line directions along the crossed-polarizer regardless of the sample stage angle (Supporting Information, Video S1). Water-swollen films were very soft and easily deformed by external force, accompanied by spherulite deformation, indicating that a large amount of water intruded into the spherulite domain. It is noted that the spherulite morphology recovered even after a large deformation (Supporting Information, Video S2) to indicate the high durability of water-swollen films. The use of a first-order retardation plate showed the subtractive birefringence in the first and third quadrants of spherulites (upper photo of Figure 3c), demonstrating positive spherulites. It seems impossible that intruding water caused a $90^{\circ}$ rotation of the macromolecular chain orientation

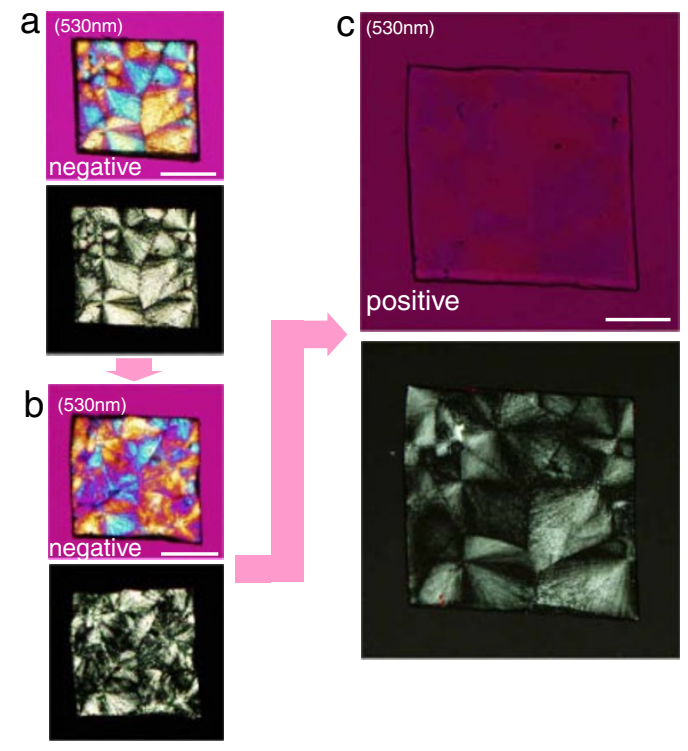

Figure 3. Crossed-polarizing microscopic photos of triblock copolymer films $(\mathrm{Dp}=25)$ taken under various conditions. The direction of crossed polarizers is the same with Figure 1b. The upper photo is taken under cross nicol with a first-order retardation plate $(\lambda=530 \mathrm{~nm})$. Scale bar: $1 \mathrm{~mm}$. a) As-cast film at $30^{\circ} \mathrm{C}$. b) A film at $30^{\circ} \mathrm{C}$ after cooling from $70^{\circ} \mathrm{C}$. c) The film swollen in water at $30^{\circ} \mathrm{C}$ following cooling from $70^{\circ} \mathrm{C}$.

inside the spherulite, but we can guess that the refractive ellipsoid sign of the aggregated portion for macromolecular chains was inversed. Comparing photos from Figure $3 \mathrm{a}$ and $\mathrm{c}$, one becomes aware of a surprising phenomenon that the polygonal spherulite morphology of the water-swollen film was the same with that in the once-disappeared, original film as-cast from the DCM solution. The aforementioned phenomenon was observed in all the copolymers prepared herein. The XRD diagram of the water-swollen film had a peak at the diffraction angle of $2 \theta=21^{\circ}$ or $23^{\circ}$ corresponding to d-spacings of 0.42 and $0.39 \mathrm{~nm}$, respectively (Figure 4). Each diffraction peak was not detected in WAXD diagrams of PEG homopolymers, 


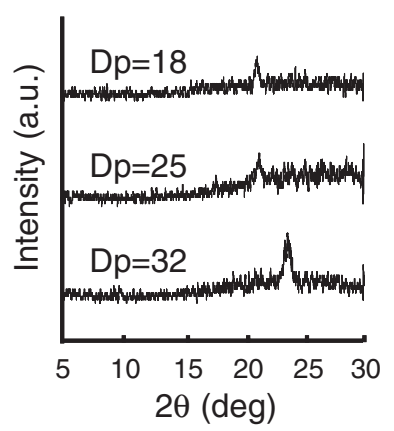

Figure 4. Wide-angle X-ray diffraction (WAXD) diagrams of water swollen films with various degrees of polymerization for PBLA units.

PBLA homopolymers, or dry films for P(BLA- $b$ EG- $b$-BLA). Since PBLA blocks were hydrophobic, diffraction peaks may be due to PBLA aggregation. According to the literature, ${ }^{15,16}$ the peptide crystals adopting the $\beta$-sheet structure showed a structural regularity of around $0.4 \mathrm{~nm}$, suggesting that the XRD peak may be due to the $\beta$-sheet structure. PBLA in water-swollen films had $\beta$-contents of $21 \%$ for $\mathrm{Dp}=$ $18,31 \%$ for $\mathrm{Dp}=25$, and $5.6 \%$ for $\mathrm{Dp}=32$, which increased during self-assembly accompanying waterintrusion. The small $\beta$-content in the $\mathrm{Dp}=32$ copolymer may be due to the reduced stability of $\beta$-sheet structures as discussed in other studies on various polypeptides. ${ }^{17}$ Spherulite sign inversion caused by water intrusion can be explained by a change in oriented components from PEG crystals into PBLA aggregations.

\section{Structure in the Melting State}

In order to determine the reason for morphological recoveries of once-disappeared spherulites, we investigated the molecular structure of dry films melting at $70{ }^{\circ} \mathrm{C}$. The XRD pattern of the film at $70^{\circ} \mathrm{C}$ (Figure 2a, middle) maintained a sharp peak at $2 \theta=2^{\circ}$ while other peaks disappeared and a broad halo appeared. In IR spectra of melting films, the shoulder attributed to $\beta$-strands (5\%) remained (Figure $2 \mathrm{~b}$, middle). The flexible PEG chain restrained by PBLA blocks containing $\beta$-form part may induce slight elasticity in melting films to maintain the macroscopic arrangement of macromolecular chains. Further heating above $140^{\circ} \mathrm{C}$ reduced film elasticity and lead to hardened films. Successive cooling from $140{ }^{\circ} \mathrm{C}$ did not induce PEG recrystallization even if the temperature was kept at room temperature for 1 week. The IR spectrum of the film cooled from $140^{\circ} \mathrm{C}$ demonstrated that PBLA chains adopted almost $100 \% \beta$-strand conformations while the film showed the $\alpha$-helix peak at 30 and $70^{\circ} \mathrm{C}$ (Figure 5a). According to the literature, ${ }^{8 \mathrm{~d}}$ PBLA homopolymer adopts almost $100 \% \beta$-conformations above $210^{\circ} \mathrm{C}$, at a temperature which is much higher than the present case, presumably due to the effects of PEGylation which increases PBLA chain mobilities. Actually, even if PEG homopolymer was mixed with PBLA homopolymer and heated at $70^{\circ} \mathrm{C}$, the $\beta$-strand and other peaks appeared at IR spectrum (upper spectrum of Figure 5b). A TEM image of the as-cast film of the $\mathrm{Dp}=25$ copolymer stained by ruthenium tetraoxide showed a thickly-stained network structure with a
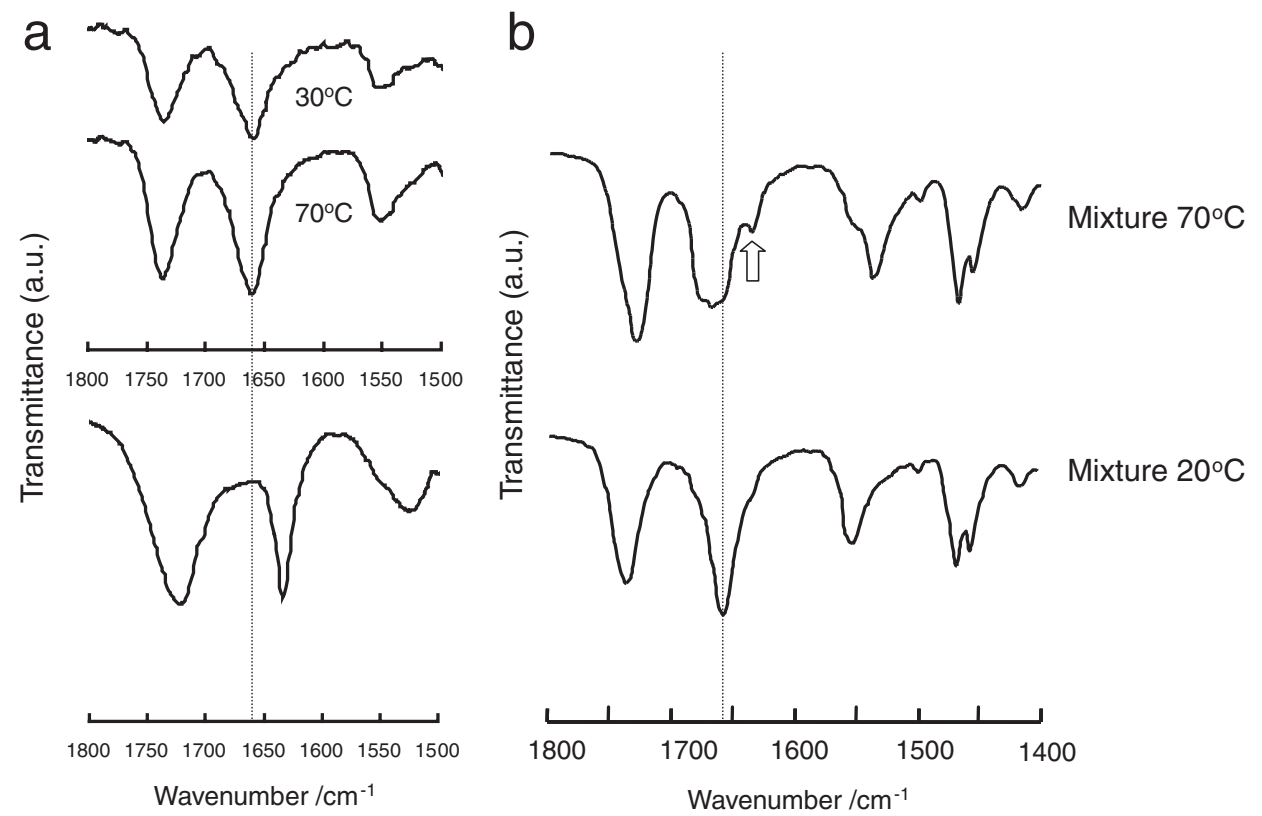

Figure 5. a) FT-IR spectra of the copolymer film measured at $30^{\circ} \mathrm{C}$ and $70{ }^{\circ} \mathrm{C}$ (upper two spectra). FT-IR spectra of the copolymer film with $\mathrm{Dp}=25$ measured at $20^{\circ} \mathrm{C}$ cooled from $140^{\circ} \mathrm{C}$ (lower spectrum). b) FT-IR spectra of a 1:1 mixture of the PBLA homopolymer with PEG measured at $20^{\circ} \mathrm{C}$ and $70^{\circ} \mathrm{C}$. Dashed lines indicate the amide I peak of $\alpha$-helix. 

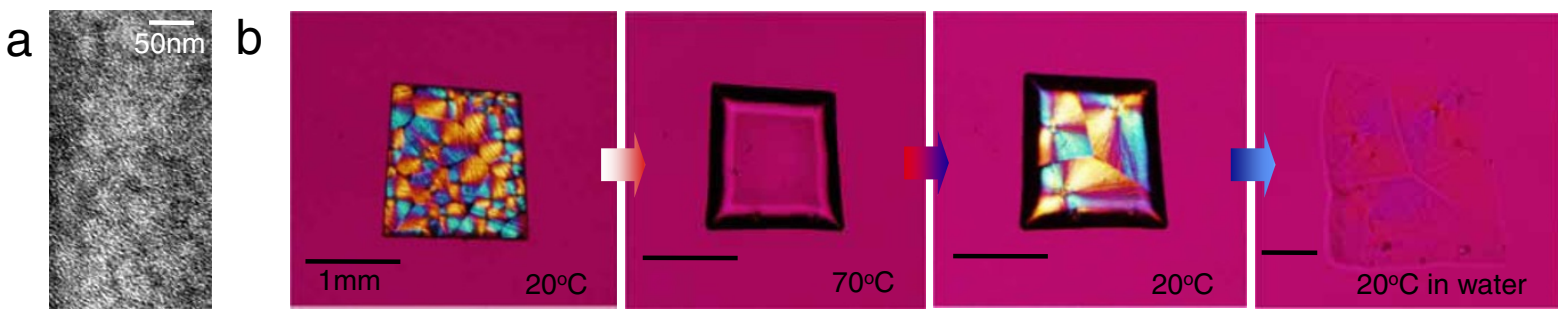

Figure 6. a) A transmission electron microscopic (TEM) photo of triblock copolymer $(\mathrm{Dp}=25)$ ultrathin cross-sections. The vacuumdried film embedded in the epoxide resin was cut in a microtome system to yield ultrathin cross-sections with a thickness less than $0.1 \mu \mathrm{m}$, followed by $\mathrm{RuO}_{4}$ staining. b) Crossed-polarizing microscopic photos of films for triblock copolymers $(\mathrm{Dp}=25)$ with hydrolyzed $2-3$ BLA units taken under a first-order retardation plate at various temperatures.

width of $8-10 \mathrm{~nm}$ (Figure 6a) which was very close to the PBLA block length, $7.7 \mathrm{~nm}$ in both sides ${ }^{18}$ and twice the d-spacing value $(8.8 \mathrm{~nm})$ of the XRD sharp peak at $2 \theta=2^{\circ}$. The PEG block $(\mathrm{PD}=460)$ is $78 \mathrm{~nm}$ long when in its $7 / 2$ helix conformation, which seems to correspond to form the thinly-stained regions with a size range of $40-80 \mathrm{~nm}$ but too long to form the thickly-stained region. Although the structure of microphase separation was not identified from such a lowresolution TEM image, we propose that polypeptide networks and/or cross-linkages remained to form sea (PEG)-island (PBLA), sea (PBLA)-island (PEG), and/or lamellar structure, even if PEG chains melted. The network structure and cross-linkage may be supported by $\beta$-sheet interchain interactions presumably generated by not only peptide group hydrogen bonds but also $\pi$-interactions for side benzene rings. In fact, the morphological recovery of the melted film after the small deformation with a less than $1 \%$ strain at $70^{\circ} \mathrm{C}$ was confirmed like a very soft elastomer, indicating that some interchain interactions remained in the melted state.

\section{Effects of Peptide Structures on Memory}

We hydrolyzed the side benzyl group of 2-3 PBLA units of the $\mathrm{Dp}=25$ copolymer to convert it into L-aspartic acid (LAA) units by interfacial reactions between DCM solutions and water for 24 hours (debenzylation was confirmed by ${ }^{1} \mathrm{H}$ NMR). The partly-debenzylated copolymer film cast from the DCM solution still formed micro-spherulites, which melted above $50{ }^{\circ} \mathrm{C}$, but the spherulite boundary was not detected at all even when a high-resolution CCD camera was used (second photo in Figure 6b). Successive cooling formed new spherulites and water immersion of the recrystallized film yielded water-swollen networks with milli-spherulites. However, spherulite boundaries in water-swollen films have the same morphology as the recrystallized film, meaning that copolymers self-assembled without memorizing the original spherulite morphology but the newly-appeared spherulite one. The network structure and cross-linkage may be broken accompanying with the PEG melting and the successive cooling reconstructed the new PBLA structures accompanying with the PEG recrystallization. IR spectra demonstrated that the Poly(BLA-co-LAA) blocks showed $\alpha$-helical conformations even in the melted state and in the waterswollen state. The aforementioned observations of film elasticity in the melt and hydrogel states suggest that the $\beta$-form of the PBLA network may play a key role in memorized self-assembly. The $\beta$-form content of the copolymer with $\mathrm{Dp}=25$ was controlled from $5 \%$ to $95 \%$ by changing the ending temperature upon heating and when the $\beta$-sheet content exceeded $75 \%$ PEG no longer recrystallized (K. T.; S. T.; M. A. manuscript in preparation). PEG recrystallization strongly interfered with the harder network that had a higher $\beta$-sheet content. Inversely, memorized selfassembly did not occur in the presence of $\alpha$-helical PBLA chains interchain interactions weaker than $\beta$-sheets, indicating that memorized self-assembly occurred via an appropriate content of $\beta$-sheet (5$75 \%)$. In the $\beta$-sheet content range, the network structure and cross-linkage may be formed in the as-cast film and kept in both melting and hydrogel states, which is the base of the memory effects.

\section{Memory Inside of Millisized Spherullites}

Even if copolymer chains were fully extended, the chain length reached to a maximum of about 400 $\mathrm{nm}$, which was much shorter than the spherulite size. Then, memorized self-assembly should occur inside of the spherulite as well as the spherulite interface. We punched out milli-spherulites to yield circular films with only one spherulite as shown in the photo of Figure 7a. Figure $7 \mathrm{~b}$ shows the microscopic photo of the circular dry film with a single spherulite under a first-order retardation plate, confirming the milliscaled positive spherulite. The milli-spherulite melted by heating and a number of positive micro-spherulites appeared upon successive cooling (Figure 7c). The following water-immersion of recrystallized films yielded water-swollen networks with only one spher- 

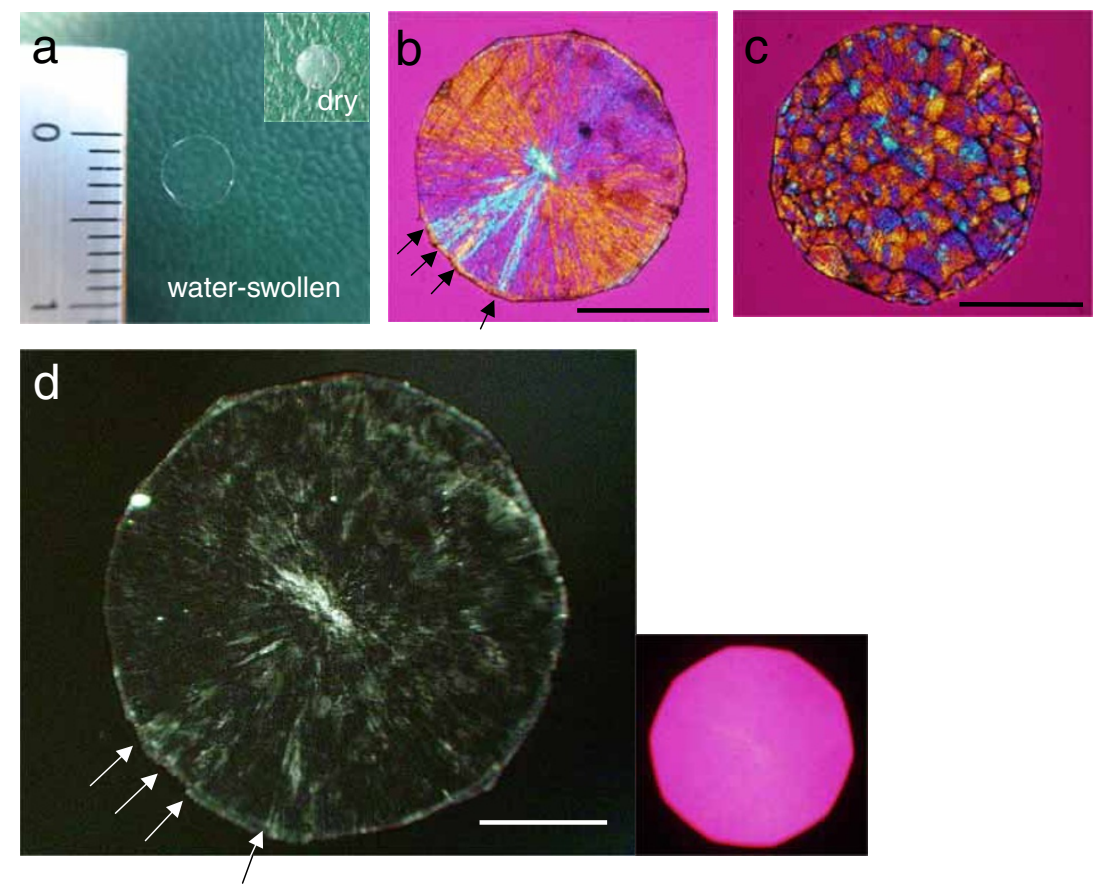

Figure 7. Representative photos of triblock copolymer films $(\mathrm{Dp}=25)$ prepared by the following procedure; the milliscaled spherulite region of a stepwise-dried film (Figure $1 \mathrm{~b}$ ) was punched out into the circular film. Scale bars: $1 \mathrm{~mm}$. a) The photo of the film in the waterswollen state. The inset photo was taken in the dry state. b) The polarized microscopic photo of the as-prepared film with a first-order retardation plate $(\lambda=530 \mathrm{~nm})$. c) The polarized microscopic photo of the film cooled from $70^{\circ} \mathrm{C}$ with a first-order retardation plate. d) The polarized microscopic photo of the film swollen in water after cooled from $70^{\circ} \mathrm{C}$. The pattern of the four arrowed lines corresponds to those of Figure $4 \mathrm{~b}$. The inset is the photo of the film center region taken under a first-order retardation plate.

ulite. Expectedly the texture of the single spherulite was the same with the once-disappeared, original single spherulite, as clearly confirmed by the relative location of four lines shown by arrows in Figure $7 \mathrm{~b}$ and $d$. The photo of the center region is inset to the right of Figure $7 \mathrm{~d}$. The additive birefringence in the second and fourth quadrants (negative spherulite) was clearly observed in the eye-lens of the microscopy, although it was only faintly shown in the inset photo. The sign of this single milli-spherulite also inversed from positive to negative by water intrusion. The birefringence in the hydrogel state may be mainly attributed to the PBLA blocks forming $\beta$-sheet extended structures. In another point of view, the water-swollen network is generally amorphous and so far the literature has only reported nanoscaled crystals such as bacterial cellulose ${ }^{19}$ and polyacrylates with long alkyl side chains. ${ }^{20}$ Herein we surpassed prior reports in that a hydrogel with only one milliscaled spherulite was prepared in this study. Memorized self-assemblies of peptide-PEG-peptide triblock chains were made not only in spherulite interfaces but also inside spherulites.

Successive, slow vaporizations of water from water-swollen films reformed dry films with original spherulite morphologies. The different spherulite morphologies were writable by successive dissolving in DCM dissolution and successive drying. Meso- morphlic memory may lead to molecule imprinting on the assembly level and nano-actuator development.

Acknowledgment. We thank Dr. Atsuhiko Ogura (NOF corporation) and Dr. Yoshishige Murata (NOF corporation) for valuable discussion about polymer syntheses.

Electronic Supporting Information Available: Polarized microscopic videos of the water-swollen films were shown in two videos. This material is available free of charge via the Internet at http://www.spsj.or.jp/ c5/pj/pj.htm

\section{REFERENCES AND NOTES}

1. a) E. Yashima, K. Maeda, and Y. Okamoto, Nature, 399, 449 (1999).

b) T. Serizawa, K.-I. Hamada, and M. Akashi, Nature, 429, 52 (2004).

2. a) P.-G. De Gennes, Macromolecules, 17, 703 (1984). b) A. Lendlein, H. Jiang, O. Junger, and R. Langer, Nature, 434, 879 (2005).

c) Y. Osada and A. Matsuda, Nature, 376, 219 (1995).

3. V. Mermall, P. L. Post, and M. S. Mooseker, Science, 279, 527 (1998).

4. J. H. Lee, T. K. Lim, Y. W. Kwon, and J. I. Jin, J. Appl. Phys., 97, 084907 (2005).

5. S. Tanaka, A. Ogura, T. Kaneko, Y. Murata, and M. Akashi, 
Macromolecules, 37, 1370 (2004).

6. T. Kaneko, S. Tanaka, A. Ogura, and M. Akashi, Macromolecules, 38, 4861 (2005).

7. S. Tanaka, A. Ogura, T. Kaneko, Y. Murata, and M. Akashi, Biomacromolecules, 5, 2447 (2004).

8. a) R. Perret and A. Skoulios, Makromol. Chem., 156, 143 (1972)

b) B. Bogdanov, A. Vidts, E. Schacht, and H. Berghmans, Macromolecules, 32, 726 (1999).

c) K. Kugo, T. Uno, H. Yamano, J. Nishino, and M. Hideo, Kobunshi Ronbunshu, 42, 731 (1985).

d) G. Floudas, P. Papadopoulos, H.-A. Klok, G. W. M. Vandermeulen, and J. Rodrigues-Hernandez, Macromolecules, 36, 3673 (2003).

e) M. L. Arnal, F. Lopez-Carrasquero, E. Laredo, and A. J. Muller, Eur. Polym. J., 40, 1461 (2004).

9. W. D. Fuller, M. S. Verlander, and M. Goodman, Biopolymers, 15, 869 (1976).

10. D. Shin, K. Shin, K. A. Aamer, G. N. Tew, and T. P. A. Russell, Macromolecules, 38, 104 (2005).

11. H. Tadokoro, Y. Chatani, T. Yoshimura, S. Tahara, and S. Murahashi, Makromol. Chem., 74, 109 (1964).
12. K. J. M. Das, S. Rastogi, P. Tandon, and V. D. Gupta, Eur. Polym. J., 37, 2295 (2001).

13. T. Ikehara, H. Kimura, and Z. Qiu, Macromolecules, 38, 5104 (2005).

14. M. J. Winningham and D. Y. Sogah, Macromolecules, 30, 862 (1997).

15. S. A. Wainwright, W. D. Biggs, J. D. Currey, and J. M. Gosline, "Mechanical Design in Organisms," Princeton University Press, Princeton, NJ, 1976, Chapters 3 and 4.

16. H. Obata and H. Kanetsuka, J. Polym. Sci. A-2, 9, 1977 (1971)

17. a) S. Ray, A. K. Das, M. G. B. Drew, and A. Banerjee, Chem. Commun., 40, 4230 (2006).

b) J. Thundimadathil, R. W. Roeske, H.-Y. Jiang, and L. Guo, Biochemistry, 44, 10259 (2005).

18. Calculated using the data of a $0.54 \mathrm{~nm}$ for $\alpha$-helix length per 1 cycle (3.6 unit), a $0.25 \mathrm{~nm}$ for $\beta$-strand length per 1 unit, and $3 \% \beta$-strand content.

19. I. Nieduszynski and R. D. Preston, Nature, 225, 273 (1970).

20. T. Miyazaki, T. Kaneko, J. P. Gong, Y. Osada, M. Demura, and M. Suzuki, Langmuir, 18, 965 (2002). 